\title{
Women composers' use of online communities of practice to build and support their careers
}

\author{
Sophie Hennekam (Audencia Business School, France) \\ Sally Macarthur (Western Sydney University, Australia) \\ Dawn Bennett (Curtin University, Australia) \\ Cat Hope (Monash University, Australia) \\ Talisha Goh (Edith Cowan University, Australia)
}

\begin{abstract}
This article examines women composers' use of online communities of practice to negotiate the traditionally masculine space of music composition while operating outside its hierarchical structures. We employed a mixed methods approach consisting of an online survey $(n=225)$ followed by 27 semi-structured in-depth interviews with female composers to explore the concept and use of communities of practice. Content analysis was used to analyse the survey responses and interpretative phenomenological analysis was used to interpret respondents' lived experiences as relayed in the interviews. The findings reveal that the online environment can be a supportive and safe space for female composers to connect with others and find support, feedback and mentorship, increase their visibility, and develop career agency through learning and knowledge acquisition. Communities of practice emerged as an alternative approach to career development for practicing female music workers and as a tool which could circumvent some of the enduring gendered challenges. The findings suggest that online communities of practice can have a positive impact on the career development and sustainability of women in male-dominated sectors such as composition.
\end{abstract}

Keywords: female composers, gender, creative industries, music, career development

Article classification: Research paper

Hennekam, S., Bennett, D., Macarthur, S., Hope, C., \& Goh, T. (2019). Female composers' use of online communities of practice to build and support their careers. Personnel Review, published online October 8 , 2019. doi: 10.1108/PR-02-2018-0059. 


\section{Introduction}

Music composition is a highly gendered occupation. From the earliest times to the present day, gender has played a role in inflecting the collective discourse of music history with a narrative that has extolled the masterworks of male composers while making invisible or incidental to that history the music of women. Yet, amidst this dominant discourse, female composers have figured, sometimes prominently (Pendle, 2010).

Gender has thus played a role in constructing a duality in which two distinct histories are traced: a dominant (male) history; and a counter (female) history, the latter emerging from research which had unearthed women's music in the 1970s. However, despite the existence of female composers, their contributions have tended to be excluded from the received standard repertoire of performed musical works. This, we argue, is a phenomenon that continues in the present day (Browning, 2016). We also suggest that it is against this backdrop that female composers have found it necessary to develop strategies for navigating the male-dominated profession of music composition.

Women composers have faced challenges throughout the history of music and their resilience and ability to adapt to their circumstances have informed the decisions they have made about their careers. Leslie and Catungal (2012), however, claim that "certain creative occupations reproduce masculinist workplace cultures and are therefore potentially harmful spaces for women" (p. 118). Given that Western art music history is characterized by an allpervasive masculine narrative, we argue that composition is one such occupation.

The study reported here adopted a mixed methods design and featured an internationally distributed, online survey which elicited responses from 225 participants (phase 1) followed in phase two by 27 in-depth interviews. The survey revealed women's use of the online environment to overcome challenges related to learning and networking. The 27 semistructured, in-depth interviews enables us to explore women's use of Communities of Practice 
(CoPs) as a tool to navigate the male-dominated space of composition and enhance career development. Our methodological approach helped us to study the prevalence of themes and simultaneously gather rich insights into the lived experiences of women composers. We posed the following research question: How can online Communities of Practice help women composers build and support their careers?

The study contributes to the literature on women composers' careers with a new understanding about how online CoPs are used to overcome perceived career barriers, as learning opportunities and to access mentorship and support. The findings expose an alternative space which might be used to circumvent some of the enduring challenges within creative industries work. Our contribution is twofold. First, we outline how online CoPs help women composers develop their careers by distinguishing four different ways of using CoPs in overcoming challenges. Second, we contribute to theory by showing that CoPs, coupled with individual agency, are helpful for career development in male-dominated sectors.

\section{Literature Review}

Challenges for female composers

The legacy of music as a predominantly male tradition has given rise to and perpetuated the gender stereotype that women do not "measure up" to the high aesthetic standards of their male counterparts. This, in turn, as Samuel (1994, p. xiv) points out, has led to "a cultural antipathy towards the concept of the female creative artist". This attitudinal antipathy has fed into the statistical representation of female composers which, as noted by Parsons and Ravenscroft (2016, p. 4), shows that they are a significant minority, comprising only approximately 20 per cent of the world's composers.

Women perceive that they face different challenges to men (Conor et al., 2015). Such challenges include, among others, interference with caring responsibilities (Banks and 
Milestone, 2011), sexual harassment (Hennekam and Bennett, 2017a) and marginalization through the active denial of their expertise by male workers (Banks and Milestone, 2011). The present study focused on two specific challenges: learning opportunities and male-dominated networks.

The first challenge concerns learning opportunities that arise from questioning and from making mistakes. Allowance for mistakes arguably improves one's performance (Gully et al., 2002) as well as one's learning and self-efficacy (Lorenzet et al., 2005). Self-efficacy - the belief in one's ability to complete a specific task or reach a goal successfully - is developed enactively (by doing), vicariously (by watching) and through encouragement by others (Bandura, 1977). Being allowed to make mistakes as one learns implies that one receives feedback (Kluger and DeNisi, 1996), which gives individuals an opportunity to see the consequences of their mistakes, learn corrective strategies, and take corrective steps (Karl et al., 1993).

It is possible that many female composers attribute their mistakes to their own limitations rather than to the fact that they have not been offered a place to learn through trialand-error, leading to frustration and reduced self-efficacy (Gist and Mitchell, 1992). Low selfefficacy, in turn, negatively impacts performance (Bandura and Locke, 2003).

Networking and socialisation have also proven to be difficult for women in the creative workforce (Wittel, 2001): hence the second challenge concerns male-dominated networks. Networks provide exposure to people in positional power, increase market visibility, and enable workers to leverage a place within the network of decision makers. Hesmondhalgh and Baker (2008) have argued that men in the creative industries have more decision-making power as they are overrepresented in such positions. Moreover, informal networks emerge as central to initiating, developing and maintaining work. Such networks or "cliques" (Manning and Sydow, 2007) are known for their potential to be both discriminatory and exclusionary (O’Brien, 2014). 
Within the performing arts, previous studies in acting (Dean, 2008) emphasize that "shared stereotypes" directly influence "the performer's access to work" (p. 173). Moreover, workers obtain work through connections and other subjective criteria (Thanki and Jeffreys, 2007). Given that networking is a key strategy for career progression, the difficulty women have in participating in networks creates significant limitations for women in the creative workforce.

\section{Theoretical framework: Communities of Practice}

Communities of practice can be defined as groups of people who share a concern or passion for something and learn how to do it better as they interact regularly (Wenger, 2011). CoP theory emerged from situated learning theory and addresses social context and power relations. In this study, we adopted a CoP lens grounded in anthropological and social theory to understand how women composers acquire knowledge and skills and develop their careers and how they respond to inequalities in the creative industries (Swan and Fox, 2010).

CoPs seek to develop members' capabilities and to build and exchange knowledge (Wenger et al., 2002) and they typically have three characteristics. Firstly, collective learning takes place in a shared domain: in this case, composition. In this study, the composers were all female, thus an additional shared domain concerned the impact of gender on their careers. Secondly, CoP members engage in joint activities and discussions, help each other and share information and opportunities. Also, they build relationships that enable them to learn from one another. In our study this included circumventing male-dominated networks which were perceived to be exclusionary (see also Christopherson, 2011).

Members of a CoP do not necessarily work together on a daily basis (Wenger, 2011). This was the case for the female composers in this study: although they mainly worked alone, the composers engaged in regular discussions online to share their thoughts and to exchange experiences and ideas. The third characteristic of a $\mathrm{CoP}$ is that members are also practitioners 
(Wenger, 2011). As a result, they share many experiences, stories and ways of addressing recurring issues. This shared repertoire of stories and case studies becomes a common knowledge base on which members can draw when facing new situations. Passion, commitment and identification with the group binds the members together for as long as the need persists (Wenger et al., 2002).

Given the ongoing challenges faced by women in the creative industries (Gill, 2014), the present study aimed to understand how female composers circumvent and resist the exclusive nature of the male-dominated networks. Drawing on CoP theory (Lave and Wenger, 1991), the findings show how female composers use online CoPs to connect, network and engage in shared learning.

\section{Methods}

Sample

This paper reports from an international study of female composers conducted in 2016 and 2017. The study involved an online survey which elicited responses from 225 participants, followed by 27 semi-structured, in-depth personal interviews. The findings were reported thematically in a series of five papers, of which this is the fifth. We first adopted a feminist lens, drawing on Bourdieu's work to highlight the reproduction of gendered habitus within the field of composition (Macarthur, Bennett, Goh, Hennekam, \& Hope, 2017). Next, we focused on the strategies employed by women composers to manage their stigmatized gender identity (Bennett, Hennekam, Macarthur, Hope, \& Goh, 2018). Our third article addressed the implications of the study for higher education. Highlighting the under-representation of music composed by women within the higher education curriculum and composers' reported unpreparedness for a career in music, we recommended a number of practical strategies for curricular and pedagogical renewal (Bennett, Macarthur, Hope, Goh, \& Hennekam, 2018). Our 
fourth article sought to understand the nature of women composers' careers and their career trajectories through the lens of human capital (Hennekam, Bennett, Macarthur, Hope, \& Goh, 2019).

Survey respondents were recruited through social media and by contacting conservatoires, educational institutions and music- and composition-related associations and networks. It can, therefore, be considered a convenience sample. Using snowball sampling (Noy, 2008), each respondent was asked to send the survey to other female composers or to identify organizations that might be interested.

At the end of the survey, respondents were asked whether they would be willing to share their story in a face-to-face, telephone or Skype discussion. Twenty-eight respondents indicated their willingness to do so and 27 respondents participated in the interview phase. It is important to acknowledge a self-selection bias as we do not know how individuals who agreed to participate differed from those who refused the invitation. The mention of CoPs in a participant's survey response was not a selection criterion for inclusion in the interview phase; hence the interview sample included individuals with and without CoPs. The sample also included composers from a wide range of music styles, demonstrating that CoPs often included a range of styles of music making. Demographic information is provided at Table 1, and stylistic information at Table 2.

[Please place Table 1 and Table 2 near here]

\section{Design}

The study adopted a mixed methods design. As such, it included both qualitative and quantitative approaches which, in combination, can provide a richer understanding of research 
problems than is possible with either approach alone (Creswell and Creswell, 2017). The mixed methods approach also enabled triangulation, which Silverman (2015) defines as the combination of multiple theories, approaches and empirical materials to produce a reliable, comprehensive and objective representation of the object of study. There are many different ways to triangulate data. In this study, we employed a sequential exploratory approach which enabled the findings generated with one method to be explored or expanded through the use of another method (Creswell and Creswell, 2017).

Our research was conducted in two phases. Phase 1 consisted of an online survey which was administered in three parts; the parts were delivered two months apart. The survey contained a total of 120 questions, of which most were open-ended questions designed to elicit in-depth responses. The survey questions were designed to elicit data on five aspects of women composers' careers: education and training; career trajectories; the impact of gender on career; how work is obtained or created; and the role of collaboration. Two questions specifically targeted respondents' use of online networks:

1. How frequently do you use each of the following online networking tools for your composing business? (Facebook, LinkedIn, own website etc.); and

2. How often do you use the following networking/marketing strategies? (conferences/peer groups, professional associations etc.).

All responses were collected, regardless of whether all three parts of the survey were completed. Respondents were presented with the aim of the study and they signed an informed consent form in which their anonymity was assured. Content analysis was used to analyse the survey data. Survey data revealed that the online environment was used to overcome challenges related to learning and networking. Intrigued by this finding, we adapted our initial interview schedule to enable further exploration, adding the question: Do you use the internet and social media for your work? If so, what for? 
Phase 2 of the study consisted of 27 semi-structured, in-depth interviews. The interviews were conducted face-to-face when possible and by telephone or Skype for those conducted over a long distance. Most interviews lasted for between one and one-and-a-half hours and were held in English, Dutch, Italian or French, depending on the preference of the interviewees.

\section{Analysis}

Phase 1 surveys were analyzed using content analysis (Stemler, 2001) with the help of NVivo software. This analytical approach was chosen in order to capture the prevalence of the themes while also allowing the lived experiences of the participants to emerge from the findings. The prevalence of the themes was determined by the use of frequency counting (Wilkinson, 2011), mindful of multiple meanings and synonyms.

In phase 2 we conducted and analyzed the in-depth interviews. As we were interested in the lived experiences of women composers how they made sense of their personal and social worlds (Smith and Osborn, 2008), we employed interpretative phenomenological analysis (IPA). This approach depends on participants' abilities to formulate their thoughts, feelings and ideas so that an interpretation of such experiences can be conducted. Moreover, it depends on the ability of the researcher to "reflect and analyse" (Brocki and Wearden, 2006, p. 88) as they have an active role in the sense-making process. The interpretation of the data can, therefore, be considered a two-stage process or a double hermeneutic in which participants first make sense of their world and then researchers make sense of the participants trying to make sense of their world (Smith and Osborn, 2008).

The analysis was inductive in nature and strongly rooted in the data (Mann and Abraham, 2006). We undertook several inter-related steps in line with Smith and Osborn's (2008) guidelines. First, more than 1,000 pages of transcripts and notes were read carefully by two authors in order to become familiar with them. The second reading created a "detailed 
interpretative analysis of themes" (Brocki and Wearden, 2006, p. 89) in which the researchers were actively trying to make sense of what was being said. Not all transcripts were equally rich and some transcripts generated more themes than others. Relevant survey data was included at this stage to enable the creation of complete cases across both the survey and interview responses.

The data was then coded. An initial codebook was established by the authors once all five researchers had independently coded the first three interviews. This codebook was then progressively modified as the codes identified in earlier cases were tested in the later ones using a process of analytic induction. Two of the researchers coded all 27 transcripts as well as the survey data; this iterative process moved towards the identification of broader themes. The last step involved creating aggregating theoretical dimensions and building relationships among the themes identified. Our interest lay in the subjective experiences of participating women composers and this method of data gave voice to the women whose lives reflected this reality and whose concerns must remain at the fore (Grbich, 2007).

\section{Findings and discussion}

The findings of this study suggest how female composers might use the online environment to build and support their careers. Our participants used the online environment as a network where they could find other women who would be difficult to access using more traditional networking methods. They described the online environment as a "safe space" where they could control the aspects that were important to them and feel comfortable about sharing work, receiving assistance and helping others. These aspects align with the concept of CoPs (Lave and Wenger, 1991; Wenger, 1998; Wenger et al., 2002), which allow adults to learn through everyday social practices rather than focusing on environments that are intentionally designed to support learning (Gray, 2004). 
Reflecting on the challenges outlined in the background to this paper, the online CoP emerged as a beneficial alternative to more traditional forms of career learning and development. In line with Gray (2004), motivations to participate in an online CoP included opportunities to learn new skills and work practices, a way to build a social and professional network of other female composers and a means to reduce the isolation that some composers felt was inherent to the process of composing.

Participating composers confirmed the presence of several challenges outlined earlier including gendered networks (true for $53 \%$ of the participants) and networked-based recruitment; participants reported that many of these challenges were gendered. Additional challenges included not being taken seriously due to their gender, experiencing difficulties when self-promoting, not having access to the same networking opportunities as men, having to deal with stereotypes, discrimination, sexism and/or (sexual) harassment, and balancing a professional career with caring responsibilities.

Despite experiencing acceptance and a level of success, I still feel like there can be a pocket of the classical community that is dismissive (to varying levels - consciously patronising, or subconsciously through small comments, etc.) of the work of composing women. My experience has included coming to terms with this attitude and how to respond. Currently my response is to treat it like any backward-thinking attitude, as not worthy of debate or cliques. (Survey respondent 37 , Australian, 29 years)

These challenges have been well-documented in the literature on work and gender; the current article employs the theoretical construct of communities of practice to examine how women respond to such challenges. With this in mind, this section is organized into four themes, each of which addresses a different challenge. First, we discuss how the online environment can provide a safe place where women can connect with other women, overcoming isolation 
and finding like-minded individuals with whom they are able to share their experiences. Second, we explain how the online environment becomes a place where female composers find support, feedback and mentorship which they struggle to find in the physical world. Third, we illustrate how women use the online environment to create marketing platforms through which they can increase visibility and engage in promotion on their own terms. Finally, we detail how female composers use the online environment to act independently and to develop career agency through new learning and knowledge acquisition.

\section{A safe place where other women can be found}

Participants highlighted the solitary nature of their composition work and, therefore, the difficulty of connecting with colleagues. The sense of isolation was compounded by the fact that there are relatively few women composers, meaning that there is more likely to be geographical distance between them, and that the women had a disproportionate number of caring responsibilities which made it difficult to attend after-hours networking opportunities. Together, these factors limited regular physical contact with other composers. The internet, which has extended the reach of human interaction beyond the geographical limitations of traditional communities, provided new opportunities for female composers to get in touch with peers, especially in women-only groups, combating feelings of isolation and being able to share experiences they may not usually talk about face-to-face.

CoPs can be big or small, local or global, face-to-face, online or blended (Wenger, 2011). Participating female composers created connections across organizational, stylistic and geographic boundaries through the use of online CoPs in the form of special interest groups, forums or social media. The ways in which these communities were experienced is elucidated below. 
I've gradually grown to get some connections on Facebook, where there are several women composer groups. That is the way that I've met women in other [geographic] States and so on. (Interviewee 16, Australian, 54 years)

It's so important and so rewarding that there is this space where you know you can go to post articles about composing or articles about female composers. (Interviewee 7, Australian, 35 years)

I have to say that I feel as a woman, completely outnumbered when I look at the [composition] feeds and the names and it's completely dominated by men. So, it is very nice to have those networks where it's just women. (Interviewee 12, Australian, 56 years)

However, groups that included both men and women were also appreciated as they could make the women feel more respected and validated as a composer.

The ones that aren't just limited to women composers made me feel very validated actually as a composer. Because I have had an opportunity to put what I do and what I think up there, I feel that I'm being respected. (Interviewee 12, Australian, 56 years).

The online space was described as a safe place in which women could express themselves and where the domination of males was absent. This was linked with the important role of an online moderator. Previous research (Harasim et al., 1995) has shed light on the different roles of moderators in formal online learning, which Berge and Collins (2000) list as simultaneously the technical trouble-shooter, educator, chairperson, facilitator and community organizer. However, we know less about the functions of moderators in online CoPs which are both voluntary and informal in nature. 
In line with Berge and Collins' (2000) research on e-moderators and Gray's (2004) study of informal learning within an online community of practice, we found that online moderators were critical to both the evolution of composers' communities of practice and the cultivation of their sense of community. Rather than moderating the exchange of information or asking questions, the moderator helped to create a $\mathrm{CoP}$ where knowledge was constructed through shared learning.

In our study, the moderator was understood as someone who facilitates learning by exploring issues that are important to the community and bringing discussions to a deeper level. The moderator was also someone who was able to understand the composers' practice and the likely challenges and opportunities encountered by members. As seen below, participants also emphasized the important role of the moderator in ensuring that members' behavior was appropriate (Gray, 2004), particularly within broader networks.

I feel it is a safe place. I mean, there have been times I've been burnt a little bit, but again, if you've got a good moderator who's not allowing any sexist comments — because there was one interaction that I had with some film composer in the States where he got a little bit out of hand really and was being quite sexist really, and horrible. But that was quickly dealt with. I think it was just noticed. I didn't even need to say anything: it was just noticed and dealt with. (Interviewee 12, Australian, 56 years)

Having that space there, and it's a safe space, I can't really think of any examples of trolling within that group because it's like a closed group; whereas in people's general feeds, they might be hijacked by "Why do you artists expect support anyway? I pay my taxes for infrastructure", or whatever. I think that's why it's so important, because even if you do have face-to-face contact with people, there's not always the space to have that running commentary. (Interviewee 7, Australian, 35 years) 
I feel like social media has really created amazing opportunities to create visibility around gender issues, as well as [to] network, follow and work with like-minded people. Despite this, there is that sector of the online community (e.g. music tech forums) where the attitude towards women is a turnoff, and I just don't even bother to engage, as much fun as the tech talk would be. (Survey respondent 37, Australian, 29 years)

The above comments illustrate that many of the women found the online space to be a valued networking place that enabled them to meet, follow and hold discussions with like-minded composers. It was also a safe, moderated place to voice opinions and share information.

The importance of trust, particularly within the skeptical online environment, can be seen in the quote below. Trust, which relates to the second aspect of Wenger et al.'s (2002) CoP theory, also emerged as a critical element of each composer's CoP. Trust underpinned both the building of relationships and members' engagement in shared learning, which often involved the disclosure of weaknesses or failures.

It's all about trust. You only participate and visit those websites if you feel you can trust the people, when you feel that this is where you belong and where you can build relationships with other composers that are just like you. (Interviewee 3, Dutch, 51 years)

\section{Support, feedback and mentorship in an online environment}

Some participants highlighted lack of support from other female composers and explained that this had hindered their career development and decreased their confidence. The online space was described as a way to surpass existing networks and look more broadly for support and feedback. 
There's support from each other online. I see when people are sharing my work on their wall on Facebook, a lot more often they are women. So, yeah, there is that sort of help.

(Interviewee 18, Canadian, 34 years)

Respondents also mentioned that there were "not enough of us to create an active support network" (Respondent 57, Australian, 31 years), suggesting that more growth is needed.

Communities of practice such as social media groups for female composers were employed to develop members' compositional practice through a variety of activities such as problem solving, seeking experience, requesting information, discussing ideas with others and through observation of more experienced composers. These were spaces in which women felt able to take risks, learn and make mistakes - something they felt they could not do in "real life". This was articulated in the following comments, the second of which articulates a common perception that women needed to be above criticism or "perfect" in order to avoid criticism based on gender.

Really good, honest criticism and then good positive suggestions about what you might do differently or what reference you might go to, what you might listen to. Or, "Have a think. Have you thought about doing it this way?" or whatever - [that] has been incredibly useful actually. (Interviewee 12, Australian, 56 years)

Men are allowed to make mistakes and learn from them, women have to be perfect from scratch. (Survey respondent 18, German, 46 years)

Participants mentioned that online communities provided them with a substitute for "real-life" mentors. Indeed, $70 \%$ of participants in the study mentioned that they had had a mentor for their composition practice and that this sometimes was entirely online. Most composers 
identified mentors who were teachers, tutors, supervisors and other composers. The mentors provided support, encouragement, inspiration and guidance to other women and helped to create new opportunities by challenging them to explore new ideas and try different approaches. Mentors also assisted with the acquisition of new technical knowledge and skills, helped composers to meet the "right people" to advance their careers, and provided critical feedback.

I have mentorship these days through a Facebook group — so it is not one particular person. But it is possible to ask all manner of questions, and to post scores. The feedback is invaluable as is looking at the help others get. I also have recently joined an orchestration on-line master class. I also occasionally get scores critiqued by a master orchestrator for the purposes of learning more about my craft. (Survey respondent 2, Australian, 56 years)

I think social media can provide women with a support system of people that they can look at: role models, and they say, "Oh, that person is not so different than I am". (Interviewee 28, American, 49 years)

\section{A different kind of networking: sharing visibility and promotion}

As mentioned earlier, networking has been identified as a significant challenge for female composers. The results of our survey and interviews demonstrate that women find in the online space an opportunity to attain visibility: to get their work out into the public domain without having to rely on perhaps hard-to-access networks. Here, they refer to broader online promotional activities but highlight the synergy between different platforms such as YouTube, free internet services and CoPs.

I struggle with networking sometimes, but promoting myself online is different because I'm hidden behind a screen in some senses, so it's easier to be more forthcoming about what 
you're good at. (Interviewee 13, English, 23 years)

I think the world is so different now with the internet, being able to have a worldwide reach. (Interviewee 17, American, 54 years)

Having recordings available. In addition to being able to send them to interested performers, they are on YouTube and have already attracted several unexpected performances in major venues. (Interviewee 9, American, 87 years)

[The] internet has been a great help. It's this mix of YouTube, having it all online and Facebook groups to give it an extra boost that really helps to get known nowadays. (Interviewee 2, Dutch, 75 years)

The sharing of best practices and the creation of a shared repertoire within an online CoP clearly helped female composers to push against the gendered boundaries and to experience an increased number of possibilities and opportunities. Participants used the online space to circumvent the "old boys" network and they created their own networks where they could provide opportunities to other female composers. As one participant concluded, "Online social media is a great equalizer"' (Interviewee 16, Australian, 54 years).

The organic, spontaneous and informal nature of CoPs makes them fairly resistant to supervision and interference (Wenger et al., 2002). Therefore, even if some male composers perceive such communities as a threat, it is difficult to stop female composers using them to their own advantage. A final feature of the networking dimension concerns the significant number of participants who reported using free internet services and other online platforms to release, market and sell recordings of their work. Whilst these are not CoPs, they illustrate the advantages of the online space in sharing and creating visibility for their work. 
In the late ' 80 s, I started going to play at cafés and bars, seeking gigs, and I still to this day can roll in quite a number of gigs per year as an acoustic folk singer-songwriter within a larger network that I have. And it's partly maintained through Facebook. (Interviewee 16, Australian, 54 years)

Usually, people already know of my work and they want to find out a bit more about the services I provide, and maybe a quote. It all happens online, it all happens by email - both the commissioned stuff and the copying work. (Interviewee 7, Australian, 35 years)

\section{Independent learning online}

Both organizations and individual workers show an increasing interest in the potential of online CoPs to enable individual workers to share knowledge and engage in workplace learning and professional development (Gray, 2004). The female composers in our study had encountered what one Dutch interviewee (aged 37 years) described as "a barrier to learning" and they recognized the unique value of online CoPs in increasing opportunities to learn. Indeed, participants noted that when interacting face-to-face in more traditional networks and learning contexts their questions often remained unanswered, hindering their ability to learn. The women stressed that this practice was in strong contradiction with men, whose mistakes and questions were experienced in a more positive way and provided opportunities to develop their craft. Some of these comments came from composers working in technology and electronic music, which are highly gendered facets of music work. They also highlight a perception that there are differences in the types and extent of support available across different music genres. 
It is very difficult in this genre to ask for help, to actually learn, because men tend to not explain things to you. You are supposed to know everything if you dare as a woman to come to an electronic studio, or you are not taken very seriously. (Survey respondent 20, German, 40 years)

A CoP can be viewed as a social learning system (Wenger, 2010) and peer-to-peer learning is typical of such communities (Gray, 2004). Participants highlighted that online learning helped them to learn independently without having to rely on formal channels of learning or the support of institutions. Again, technology and electronic music came to the fore.

The macho attitude towards knowledge of software is very irritating. The women I've spoken to in my field say that they've mostly learned programs intuitively, or by tinkering. Using these programs as a tool rather than a means to show knowledge is how many of us have learned, and the need to prove this knowledge is aggravating. (Survey respondent 6 , Finnish, 26 years)

Working in electronic music, web-based forms and machinima [films made from virtual reality platforms] gives women a way to circumvent the old and young boys' networks and styles of communication. I see a great surge of excellent and creative work by women who are working mostly solo in these areas. (Survey respondent 8 , Canadian, 48 years)

CoPs have multiple levels and types of participation, and the interplay between experienced members and newcomers was an important dimension of passing on knowledge as well as facilitating the creation of new knowledge and insights (Grugulis and Stoyanova, 2011). This emerged clearly from the findings, with less established composers expressing their reliance on more senior colleagues for insights and advice. 
I enjoy certain forums and social media as I feel I make a difference there. New, young composers are still learning the ropes and often ask questions that I asked myself, too, when I was younger. Sharing my personal experiences with them maybe helps them to go further and develop themselves, allowing female composers to become more established. (Interviewee 2, Dutch, 75 years)

It is important to acknowledge that CoPs do not necessarily lead to positive outcomes. For example, some participants reported that online communities increased competition: "the competition is deadly, so I get no support outside of my friendship group" (Survey respondent 27, Australian, 43 years). Others mentioned that "nothing can replace face-to-face interaction and socialization, making the online environment interesting but by no means enough to overcome the structural inequalities" (Interviewee 1, Dutch, 44 years). Finally, some instances of conflict and exclusion were reported in the online space, suggesting that these spaces are not always positive: "I once got blocked, because another woman didn't like me, I think. I felt rejected and excluded. I thought this was a space for us, where there would be solidarity (Interviewee 4, Dutch, 36 years).

In the following section we discuss the practical and theoretical implications and outline the limitations of the study. We then provide suggestions for further research to enhance our understanding of the usefulness of CoPs in overcoming the gendered challenges faced by women composers.

\section{Practical and theoretical implications}

The findings hold implications for organizations and for individual composers. Indeed, one of the novel contributions of this study is that it worked with a disparate group rather than looking at a CoP within or across specific organizations. We begin with Hennekam and Bennett's study (2017b) which identified common challenges for workers in the creative industries and highlighted the precarious nature of creative industries work. The present study contributes to 
the literature on women composers' careers by illustrating how CoPs can be used as an individual approach to overcoming gendered and other career challenges. We argue that CoPs can be a valuable strategy because they enhance opportunities for learning, mentorship, risktaking, support and advice, all of which are positively related to career development.

Wittel (2001) is one of several scholars to argue that female creative workers encounter more difficulties when they attempt to network. While this challenge is well-documented (see also Christopherson, 2011; Manning and Sydow, 2007), less is known about the ways in which women attempt to overcome such challenges. The first implication is that the online space and, more specifically online CoPs, can underpin alternative approaches to career development learning for female composers. These online spaces provide a place for women to develop, learn and extend their careers by participating with like-minded others whilst still maintaining more traditional networks if so desired. CoPs are distinct from other online groups as they entail a shared domain which becomes a source of identification. This identity creates a sense of commitment to the community as a whole. For women composers, online CoPs provide a safe environment in which women can build and maintain their own professional networks rather than relying on male-dominated networks.

The second implication refers to perceived barriers to learning as a result of which female composers felt that their skills development was being impeded. Online CoPs provided the women with an alternative platform in which to promote and learn, make mistakes and ask questions. As such, the CoP was often used to generate developmental opportunities through mentorship, referral or peer learning. The online space appears to overcome the discriminatory and exclusionary environments experienced by many female composers in more traditional study and creative workplace situations. Of note, composers described the online environment as a place where mistakes had a lesser impact on confidence and career progression and where there were opportunities to learn in a safe and supportive network. 
We also make a theoretical contribution. Previous research has shown the value of CoPs in the creative industries, especially when navigating project-based work (Bettiol and Sedita, 2011). Moreover, researchers including Fox (2000) have emphasized the role of CoPs in organizational learning, specifically when seeking to overcome unequal power relations. This is a crucial aspect of CoPs because creative workers' power and legitimacy grow as a result of getting their work known and being well-regarded by their peers (McLeod et al., 2011).

Building on this extant work, we show how women use CoPs to address gendered career challenges by seeking out other women who find themselves in similar situations. This requires an understanding of how women's common goals fit within the context of the larger composition community, and the ability of individuals to identify with a domain within the community itself (Bond and Lockee, 2018). Online communities provide clearly identifiable domains through the labelling of groups: for example, 'Women in Composition' is the title of an active, private Australian-based Facebook group with over 1600 members.

Yet, from a feminist perspective, we should ask how effective these segregated online communities of practice are at improving women's representation. Do they really serve a worthwhile purpose, or do they perpetuate division? Writing about feminist spirituality and gender, Murphy (2014) suggests that feminist, online women-only spaces should not be exclusively the domain of women; rather, they should embrace the whole spectrum of diversity, including men who are committed to feminist agendas. She also argues that the binary concept of gender "that underlies women-only spaces creates a difficult choice for those people whose gender identity does not fit into one of two categories" (p. 39). For Murphy, "all-genders" spaces would solve this problem. In the domain of the composer, such spaces appear to require strong moderation and the resolve of the group to maintain respectful and non-gendered behaviors. 
Related to this issue, the concept of a "woman-only" space also implies the dichotomy between male and female in which the term "male" is valorized and that of "female" is devalued. As Grosz (1989) writes, “dichotomies are inherently non-reversible, non-reciprocal hierarchies, and thus describe systems of domination" (p. xvi). Women-only online communities of practice could thus be sidelined by those spaces in which important decisions about the broadcasting, commissioning and performance of music are made.

While online communities of practice are valuable for female composers and other groups of practitioners who are geographically dispersed or otherwise isolated, Wenger (2011, p. 48) agrees that "the danger of a pure web-based presence for a community is its timelessness. It is always possible to participate, but by the same token, there is never a special occasion to participate". We contend that these online communities of practice should be supplemented by other opportunities to learn, connect and share best practices, preferably in a blended (online and offline) format. This implication extends to arts organizations and to higher education providers, who could encourage students to participate in multi-mode CoPs during their studies and could facilitate access to learning opportunities for graduates. Blended and multi-gender CoPs are also likely to diminish gendered stereotypes by facilitating regular exchange and dialogue among members.

While online CoPs provide a range of advantages, they are not without shortcomings. Wenger (2011) and Wenger et al. (2002), for example, articulate distinct challenges related to a CoP's visibility and presence, size, affiliation, priorities and cultural differences. In order to reap the benefits of online communities of practice, members need to take into account and deal with social, cultural and, in some cases, organizational issues that may result (Wenger, 2011). The present study was unable to examine differences between open versus closed CoPs, moderated versus unmoderated CoPs and differences in number of memberships and posts per months, for example; this would be a valuable and timely topic for future research. 


\section{Limitations and suggestions for future research}

Every study has limitations and we outline these in this section. First, the use of a convenience sample implies that the sample is not representative. While participating composers came from many different countries, certain parts of the world such as Africa and South America are absent or strongly under-represented. We do not claim that our findings can be generalized; rather, the results provide interesting building blocks and merit further investigation.

Second, the sample consisted of only female composers in Western Art music and most of them created acoustic music. It is important to acknowledge the difficulties faced by other groups such as LGBTQIA+ minorities. Including other minorities and exploring the intersection of multiple disadvantaged social groups is an important avenue for future research. Indeed, some challenges and women's use of CoPs to overcome them might also hold true for other minority groups. Similarly, extending our study to female creative workers in other subsectors would enhance our understanding of the usefulness of the online space in overcoming gendered challenges.

In addition, the use of CoPs was raised spontaneously by the participants when they completed the survey. As a consequence, participants reported mainly positive experiences. We are mindful that CoPs might also encounter challenges such as conflict. Similarly, some CoPs are likely to be more useful than others and might be more beneficial for some women but not for others. Future research might explore for whom and under which conditions CoPs are useful for career development.

Finally, it would be interesting to discover whether the safety experienced in the online environment translated into learning and career opportunities that are equally significant as those discovered in other environments. The study revealed information about the ways in 
which women work online but much less about the real impact of this in the longer term. This would be an interesting dimension for further study.

\section{Concluding comments}

The article highlights the importance of online CoPs as a means by which female composers circumvent male-dominated spaces. They were perceived as unique opportunities to connect with other women in the field, to find support, feedback and mentorship and to engage in shared learning. The findings expose an alternative space for career development amongst female creative workers and provide information that might be used to circumvent some of the enduring challenges within the creative industries.

\section{Funding}

This research has been partially supported by the Junior Professor Award awarded to the first author from the Federation Nationale pour l'Enseignement de la Gestion des Entreprises (FNEGE) in France.

\section{References}

Bandura, A. (1977), "Self-efficacy: Toward a unifying theory of behavioral change", Psychological Review, Vol. 84 No. 2, pp. 191-215.

Bandura, A. and Locke, E. A. (2003), "Negative self-efficacy and goal effects revisited", Journal of Applied Psychology, Vol. 88 No. 1, pp. 87-99.

Banks, M. and Milestone, K. (2011), “Individualization, gender and cultural work”, Gender, Work and Organization, Vol. 18 No. 1, pp. 73-89.

Bennett, D., Hennekam, S., Macarthur, S., Hope, C. and Goh, T. (2018). Hiding gender: How female composers manage gender identity. Journal of Vocational Behavior. 
Bennett, D., Macarthur, S., Hope, C. Goh, T. and Hennekam, S. (2018). Creating a career as a woman composer: Implications for music in higher education. British Journal of Music Education, 35(3), 237-253.

Berge, Z. L. and Collins, M. P. (2000), "Perceptions of e-moderators about their roles and functions in moderating electronic mailing lists", Distance Education: An International Journal, Vol. 21 No. 1, pp. 81-100.

Bettiol, M. and Sedita, S. R. (2011), "The role of community of practice in developing creative industry projects", International Journal of Project Management, Vol. 29 No. 4, pp. 468-479.

Bond, M. A. and Lockee, B. B. (2018), "Evaluating the Effectiveness of Faculty Inquiry Groups as Communities of Practice for Faculty Professional Development”, Journal of Formative Design in Learning, pp. 1-7.

Brocki, J. M. and Wearden, A. J. (2006), “A critical evaluation of the use of interpretative phenomenological analysis (IPA) in health psychology", Psychology and Health, Vol. 21 No. 1, pp. 87-108.

Browning, J. (2016), "Equal Arts: Discussion Paper", available at: http://www.cacwa.org.au/documents/item/506 (accessed 14 February 2018).

Christopherson, S. (2011), "Connecting the Dots: Structure, Strategy and Subjectivity in the Entertainment Media”, in Deuze, M. (Ed.), Managing Media Work, Sage, Thousand Oaks CA, pp. 179-90.

Conor, B., Gill, R. and Taylor, S. (2015), “Gender and creative labour”, The Sociological Review, Vol. 63 No. S1, pp. 1-22.

Creswell, J. W. and Creswell, J. D. (2017), Research design: Qualitative, quantitative, and mixed methods approaches. London: Sage publications.

Dean, D. (2008), "No human resource is an island: Gendered, racialized access to work as a 
performer", Gender, Work and Organization, Vol. 15 No. 2, pp. 161-81.

Fox, S. (2000), "Communities Of Practice, Foucault And Actor-Network Theory”, Journal of Management Studies, Vol. 37 No. 6, pp. 853-868.

Gill, R. (2014), “Academics, Cultural Workers and Critical Labour Studies”, Journal of Cultural Economy, Vol. 7, No. 1, pp. 12-30.

Gist, M. E. and Mitchell, T. R. (1992), "Self-efficacy: A theoretical analysis of its determinants and malleability", Academy of Management Review, Vol. 17 No. 2, pp. $183-211$.

Gray, B. (2004), "Informal learning in an online community of practice", Journal of Distance Education, Vol. 19 No. 1, pp. 20-35.

Grbich, C. (2007), Qualitative data analysis an Introduction, Sage Publications, London.

Grosz, E. (1989), Sexual subversions: Three French feminists, Allen \& Unwin, Sydney.

Grugulis, I. and Stoyanova, D. (2011), “The missing middle: communities of practice in a freelance labour market”, Work, Employment and Society, Vol. 25 No. 2, pp. 342-351.

Gully, S. M., Payne, S. C., Kiechel Koles, K. L. and Whiteman, J. K. (2002), "The impact of error training and individual differences on training outcomes: An attribute-treatment interaction perspective", Journal of Applied Psychology, Vol. 87, No. 1, pp. 143-155.

Harasim, L., Hiltz, S. R., Teles, L. and Turoff, L. (1995). Learning networks, MIT Press, Cambridge, MA.

Hennekam, S. and Bennett, D. (2017a), "Sexual harassment in the creative industries: Tolerance, culture and the need for change", Gender, Work \& Organization, Vol. 24 No. 4, pp. 417-434.

Hennekam, S. and Bennett, D. (2017b), “Creative industries work across multiple contexts: common themes and challenges", Personnel Review, Vol. 46 No. 1, pp. 68-85. 
Hennekam, S., Bennett, D., Macarthur, S., Hope, C. and Goh, T. (2019). An international perspective on managing career as a woman composer. International Journal of Arts Management, 21(3).

Hesmondhalgh, D. and Baker, S. (2008), "Creative work and emotional labour in the television industry", Theory, Culture \& Society, Vol. 25 No. 7-8, pp. 97-118.

Karl, K. A., O’Leary-Kelly, A. M. and Martocchio, J. J. (1993), “The impact of feedback and self-efficacy on performance in training”, Journal of Organizational Behavior, Vol. 14 No. 4, pp. 379-394.

Kluger, A. N. and DeNisi, A. (1996), “The effects of feedback interventions on performance: A historical review, a meta-analysis, and a preliminary feedback intervention theory", Psychological Bulletin, Vol. 119 No. 2, pp. 254-284.

Lave, J. and Wenger, E. (1991), Situated learning: Legitimate peripheral participation, Cambridge University Press, Cambridge, UK.

Leslie, D. and Catungal, J. P. (2012), "Social justice and the creative city: class, gender and racial inequalities", Geography Compass, Vol. 6 No. 3, pp. 111-22.

Lorenzet, S. J., Salas, E. and Tannenbaum, S. I. (2005), "Benefiting from mistakes: The impact of guided errors on learning, performance, and self-efficacy", Human Resource Development Quarterly, Vol. 16 No. 3, pp. 301-322.

Macarthur, S., Bennett, D., Goh, T., Hennekam, S., \& Hope, C. (2017). The rise and fall, and the rise (again) of feminist research in music: 'What goes around comes around'. Musicology Australia, 39(2), 73-95.

Mann, E. and Abraham, C. (2006), “The role of affect in UK commuters' travel mode choices: An interpretative phenomenological analysis", British Journal of Psychology, Vol. 97 No. 2, pp. 155-176.

Manning, S. and Sydow, J. (2007), “Transforming creative potential in project networks: how 
TV movies are produced under network-based control”, Critical Sociology, Vol. 33 No. $1 / 2$, pp. 19-42.

McLeod, C., O'Donohoe, S. and Townley, B. (2011), "Pot noodles, placements and peer regard: creative career trajectories and communities of practice in the British advertising industry", British Journal of Management, Vol. 22 No. 1, pp. 114-131.

Murphy, M. (2014), "Feminist spirituality and gender lessons from beyond women-only space", Communities, Vol. 162, pp. 38-40.

Noy, C. (2008). Sampling knowledge: The hermeneutics of snowball sampling in qualitative research. International Journal of social research methodology. Vol 11 No. 4, pp. 327 34.

O’Brien, A. (2014), “"Men own television': why women leave media work”, Media, Culture \& Society, Vol. 36 No. 8, pp. 1207-1218.

Parsons, L. and Ravenscroft, B. (2016), “Analytical Essays on Music by Women Composers: Concert Music, 1960-2000”, available at: http://www.oxfordscholarship.com/view/10.1093/acprof:oso/9780190236861.001.000 1/acprof-9780190236861 (accessed 2 May 2017)

Pendle, K. (2010), Women in Music: A Research and Information Guide, Routledge, New York. Samuel, R. (1994), “Women's Music: A Twentieth-Century Perspective”, in Sadie J. A. and Samuel, R. (Eds.), The New Grove Dictionary of Women Composers, MacMillan, London, pp. xiii-xviii.

Silverman, D. (2015), Interpreting qualitative data. London: Sage.

Smith, J. A. and Osborn, M. (2008), "Interpretative Phenomenological Analysis”, in Smith J.

A. (Ed.), Qualitative Psychology A practical guide to research methods, Sage Publications, London, pp. 53-80.

Stemler, S. (2001), “An Overview of Content Analysis.” Practical Assessment, Research \& 
Evaluation, Vol. 7, No. 17, p. 1-5.

Swan, E. and Fox, S. (2010), "Playing the Game: Strategies of Resistance and Co-optation in Diversity Work", Gender, Work \& Organization, Vol. 17 No. 5, pp. 567-589.

Thanki, A. and Jeffreys, S. (2007), "Who are the fairest? Ethnic segmentation in London's media production", Work Organisation, Labour and Globalisation, Vol. 1 No. 1, pp. $108-18$.

Wenger, E. (1998), Communities of practice: Learning, meaning, and identity, Cambridge University Press, Cambridge UK.

Wenger, E. (2010), “Communities of practice and social learning systems: the career of a concept”, Social learning systems and communities of practice, Vol. 3, pp. 179-198.

Wenger, E. (2011), “Communities of practice: A brief introduction”, available at: https://scholarsbank.uoregon.edu/xmlui/handle/1794/11736 (accessed 19 July 2017).

Wenger, E., McDermott, R. and Snyder, W. M. (2002), Cultivating communities of practice: A guide to managing knowledge, Harvard Business School Press, Boston MA.

Wilkinson, R. (2011), “Changing Interactional Behaviour: Using Conversation Analysis in Intervention Programmes for Aphasic Conversation", in Applied Conversation Analysis: Changing Institutional Practices, Basingstoke: Palgrave Macmillan, pp. 3253.

Wittel, A. (2001), “Toward a network sociality”, Theory, Culture and Society, Vol. 18 No. 6, pp. 51-76. 
Table 1: Demographics

Survey sample

Interview sample ( $\%$ and count)

Country $\quad$ Europe $27 \%$

Europe 51.9\% (14)

North America 31\%

North America 22.2\% (6)

Oceania $27 \%$

Oceania $25.9 \%(7)$

Africa, Asia and South America 3\%

Not specified $18 \%$

Table 2: Compositional Genres of Survey participants.

\begin{tabular}{|l|l|}
\hline Contemporary Classical & 121 \\
\hline New Music/Experimental & 36 \\
\hline Theatre/Film & 15 \\
\hline Electroacoustic & 13 \\
\hline Mixed genre & 9 \\
\hline Contemporary/Popular & 7 \\
\hline Sound art & 5 \\
\hline World Music & 5 \\
\hline Jazz & 4 \\
\hline New age & 2 \\
\hline Performance Art & 1 \\
\hline Unsure/No response & 7 \\
\hline Total & 225 \\
\hline
\end{tabular}

